additional partial bond in the critical complex. The exchange we described ${ }^{3}$ involves the polarisations

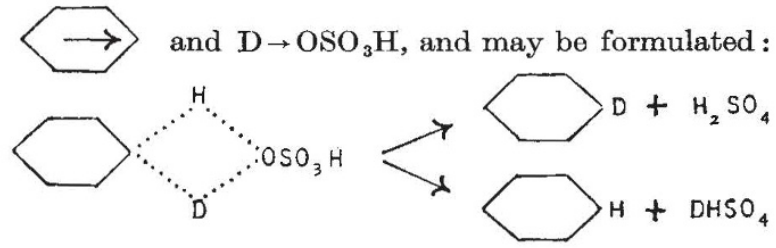

This mechanism is analogous to that originally illustrated by Ingold and Ingold for nitration ${ }^{4}$.

University College, London.

C. K. INGOLD.

C. G. RAISIN.

C. L. WIrson.

1 Ingold and Shaw, $J_{j}$ Chem. Soc., 2918 ; 1929.

Ingold and Ingold, $\dot{J}$. Chem. Soc., $1310 ; 1926$. Ingold, Rec. Trav. Chim.. 48, 797; 1929. J. Chem. Soc., 1120; 1933. Chem. Rev. (in press). 3 NATURE, 134, 734, Nov. 10,1934

'loc. cit.

\section{Spectra and Latent Energy in Flame Gases}

Prof. W. T. David in the first paragraph of his letter under this title ${ }^{1}$ makes two points about the afterglow in the gases fromflamesor explosivereactions; the first that the temperatures determined by the sodium flame reversal method are too high, compared presumably with the platinum resistance method, the second that 'long-lived' luminous products account for a considerable proportion of the heat of combustion, while further on he mentions 15 per cent.

The sodium reversal method demands that the atoms of sodium are in thermodynamic equilibrium with the gas, and this is not necessarily the case if a small percentage of metastable excited molecules are present which are capable of communicating energy more easily to the sodium atoms ${ }^{2}$. As regards the second point, the energy associated with the change of metastable $\mathrm{CO}_{2}$ to the normal state seems to be of the order of at least 80 cal. per mol., as indicated by the photographs of the diffuse banded spectra ${ }^{3}$ and probably higher ${ }^{4}$. Since the heat of combustion of $\mathrm{CO}$ is only 67.6 cal. per mol., Prof. David's value for the proportion of the heat of combustion latent in the metastable molecules would indicate that 13 per cent of the molecules were in such a state, and if these all returned to the normal state by emitting light, the efficiency of illumination by the CO flame would be far greater than experience indicates. As one of us wrote in the discussion of one of Prof. David's papers, he is possibly correct in ascribing the luminosity or afterglow to metastable molecules, but the amount of energy which he connects with them seems altogether unreasonable.

$$
\begin{aligned}
& \text { Thermodynamics Dept. } \\
& \text { Clarendon Laboratory, } \\
& \text { Oxford. } \\
& 1 \text { NATURe, 134, 663, Oct. 27, } 1934 . \\
& 2 \text { cf. Ubbelohde, J.Chem. Soc., 977; } 1933 . \\
& { }^{3} \text { Fowler and Gaydon, Proc. Roy. Soc., A, 142, 362; } 1933 . \\
& \text { - cf. Goodeve, Trans. Faraday Soc., 30, 63; } 1933 .
\end{aligned}
$$

Messrs. Egerton and Ubbelohde appear to agree that flame temperatures determined by the sodium line reversal method may be too high. The evidence that they are, in general, too high, seems to me to be overwhelming and has been recently reviewed ${ }^{1}$. They are not only in general too high (by some hundreds of degrees centigrade) when compared with temperatures determined by the platinum resistance method, but sometimes also when compared with the ideal calculated temperatures.

In one instance only, so far as our experiments have gone, are the platinum and sodium temperatures in approximate agreement, namely, for flames resulting from the combustion of a 'correct' CO-air mixture. For this mixture burning at atmospheric pressure the sodium flame temperatures determined by Loomis and Perrot ${ }^{2}$ and by Ellis and Morgan ${ }^{3}$ are $1900^{\circ} \mathrm{C}$. and $1930^{\circ} \mathrm{C}$. The maximum value determined by Griffiths and Awbery ${ }^{4}$ by the same method is considerably lower, about $1780^{\circ} \mathrm{C}$. Our platinum-rhodium wire resistance measurements yields for the same mixture burning at the same pressure a temperature of approximately $1870^{\circ} \mathrm{C}$. (slightly extrapolated from a series of experiments on 'weak' and 'over-rich' mixtures 5 ).

Confining attention to this mixture, in regard to which the approximate flame temperature can scarcely be in doubt, calculation shows that less than 80 per cent of the heat of combustion has been released in the flame gases, and, as the platinum wire experiments show that a state of equilibrium has been reached ${ }^{6}$, there would seem to be a clear case for postulating a long-lived latent energy within the flame gases amounting to more than 20 per cent of the heat of combustion.

Messrs. Egerton and Ubbelohde think it likely that the afterglow of the flame gases is to be attributed to metastable molecules, but consider it unreasonable to suggest that the whole of this large amount of latent energy is associated with them. They make a strong case for this view, arguing upon the assump. tions that carbon dioxide can possess only one metastable state and that the normal state can only be reached by the emission of light. But our knowledge of the metastable states of triatomic molecules is at present at a very elementary stage, and exclusive quantitative criticism would seem to be a little premature. It may, therefore, be worth while keeping metastability in mind as a possible seat of the longlived latent energy, though, as stated in my previous letter, another explanation would appear to be possible.

Whatever may be the explanation, it seems certain that there exists in flame gases a long-lived latent energy, which is large in amount in flames and relatively small in amount in large vessel explosions. The object of my letter was to point out a probable connexion with Prof. Bone's spectrograms for flames and explosions.

W. T. David.

Engineering Department, University,

Leeds. Nov. 9.

1 "The Sodium Line Reversal Method of Determining Flame Temperatures", Engineering, Nov. 2, 1934.

Ind. and Eng. Chem., Oct. 1928, 1007.

3 Trans. Faraday Soc., 28, 826; 1932.

- Proc. Roy. Soc., A, 123, 401; 1929.

Phil. Mag., 17, 176; 1934.

-Phil. Mag., 17, 174; 1934. 18, 230 ; 1934.

\section{Chemical Reactivity and Absorption of Light}

In recent publications ${ }^{1}$, it has been shown that the absorption of light by a mixture of two reacting substances is greater than the absorptions of the reacting substances considered separately. Thus the absorp. tion in the visible and ultra-violet regions by a mixture of $N / 400$ aqueous iodine and $2 N$ potassium oxalate is much greater than the light absorption by $N / 800$ aqueous iodine and $N$ potassium oxalate taken 